\author{
Marquette University \\ e-Publications@Marquette
}

College of Nursing Faculty Research and

Publications

Nursing, College of

4-2014

\title{
Factors Associated with the Emotional Distress of Women Family Members of Adults with Serious Mental Illness
}

Jaclene Zauszniewski

Case Western Reserve University

Abir K. Bekhet

Marquette University, abir.bekhet@marquette.edu

Follow this and additional works at: https://epublications.marquette.edu/nursing_fac

Part of the Nursing Commons

\section{Recommended Citation}

Zauszniewski, Jaclene and Bekhet, Abir K., "Factors Associated with the Emotional Distress of Women Family Members of Adults with Serious Mental Illness" (2014). College of Nursing Faculty Research and Publications. 298.

https://epublications.marquette.edu/nursing_fac/298 


\title{
Marquette University
}

\section{e-Publications@Marquette}

\section{Nursing Faculty Research and Publications/College of Nursing}

This paper is NOT THE PUBLISHED VERSION; but the author's final, peer-reviewed manuscript. The published version may be accessed by following the link in the citation below.

Archives of Psychiatric Nursing, Vol. 28, No. 2 (April 2014): 102-107. DOI. This article is (C) Elsevier and permission has been granted for this version to appear in e-Publications@Marquette. Elsevier does not grant permission for this article to be further copied/distributed or hosted elsewhere without the express permission from Elsevier.

\section{Factors Associated with the Emotional Distress of Women Family Members of Adults with Serious Mental Illness}

\author{
Jaclene A. Zauszniewski
}

Case Western Reserve University

Abir K. Bekhet

Marquette University College of Nursing

\section{Abstract}

Women family members of adults with serious mental illness are at great risk for emotional distress. This study examined associations between characteristics of 60 women (age, race, and education), their relatives with mental illness (age, diagnosis, and years since diagnosis), and the family situation (relationship, living arrangements, and care provided) and symptoms of emotional distress. Depressive symptoms were greater among those with younger, non-sibling relatives. Anxiety was greater among Caucasians and those with a recently diagnosed family member, particularly bipolar disorder. Anger was associated with providing direct care. The findings are informative for tailoring interventions to minimize emotional distress in future family caregivers. 
Each year, more than $22 \%$ of the U.S. population are affected by a mental disorder considered serious, including schizophrenia, bipolar disorder, major depression, and anxiety (Jonas et al., 2012). Current estimates of specific categories of mental disorders indicate that approximately 2.4 million adults have schizophrenia, 5.7 million have bipolar disorder, 14.8 million have major depression, and 40 million have an anxiety disorder, which may include panic disorder, post-traumatic stress disorder, obsessive-compulsive disorder, generalized anxiety disorder or phobias (NIMH, 2008). The costs of these disorders to the nation are believed to exceed $\$ 300$ billion annually, including expenditures for health care, lost wages, and disability benefits (Insel, 2008).

One in four families has at least one member with a mental disorder and family members often become their primary caregivers (World Health Organization, 2013). As a result, a large percentage of adults with serious mental illness are able to live in the community rather than being institutionalized. Over $75 \%$ of persons with serious mental illness who are discharged from treatment return, and up to $90 \%$ of those not living in the same household with other family members remain in close contact (Shankar \& Muthuswamy, 2007). Thus, many of those with serious mental illness are receiving some type of support, assistance, or care from another family member, ranging from meeting personal and health care needs to providing instrumental and financial support (Lively et al., 2004, Pernice-Duca, 2010).

The burden of mental disorders on family members is often ignored, in part because given its subjective and personal nature, it is difficult to assess and measure (Shamsaei et al., 2013). Yet, a family member's serious mental illness has been reported to have a significant effect on family members' health, well-being, and quality of life (Angermeyer et al., 2006, Fan and Chen, 2011, Møller et al., 2009, Zauszniewski et al., 2009b, Zendjidjian et al., 2012). Indeed, research has shown that family members of persons with serious mental illness experience distress, anxiety, depression, and economic strain (Dore and Romans, 2001, Shamsaei et al., 2013, Tranvag and Kristofferson, 2008).

The research shows that $80 \%$ of those who provide care to persons with mental illness are women [World Federation of Mental Health (WFMH), 2010]. The family member who provides the help or support needed may be mother, wife, sister, daughter, aunt, or other, more distant relative (Chan, 2011, Dore and Romans, 2001, Weimand et al., 2010). Caring for a family member with serious mental illness may cause considerable psychological distress and adversely affect the mental health of women family members (Jiji, 2007, Zauszniewski et al., 2009b).

Although the literature is replete with studies describing the distress experienced by family members of persons with mental illness, the manner in which the distress is conceptualized and measured differs. For example, researchers have referred to the distress as psychological (e.g., Burns et al., 2013, Kim et al., 2003, Mak and Cheung, 2012, Moller-Leimkuhlerm and Wiesheu, 2012, Remko et al., 2013, Taylor et al., 2008) or emotional (Dixon et al., 2011, Lucksted et al., 2013, Vaddadi et al., 2002); some did not describe the type of distress (e.g., Murray-Swank et al., 2007) and others have used the two terms interchangeably (e.g., Manguno-Mire et al., 2007). The multiple and diverse meanings that have been assigned to the distress experienced by family members of persons with mental illness make it difficult to capture their emotional status and to synthesize the research findings.

In addition, the distress experienced by family members of persons with mental illness has been operationalized mostly in terms of their inability to perform daily functions and their experience of specific psychological, somatic, and relational symptoms or behaviors using general measures of mental health; few have measured psychological distress using depression scales (e.g., Kim et al., 2003, Taylor et al., 2008). Most studies of psychological distress used the General Health Questionnaire (Goldberg, 1978) while most studies of emotional 
distress used the Brief Symptom Inventory (Derogatis, 1993). However, none of the studies of distress in family members of persons with mental illness have focused specifically on the examination of anxiety, depression, and anger as symptoms of emotional distress (Pilkonis et al., 2011) as the study reported here was designed to do.

\section{Emotional distress and caring for the mentally ill}

Family members of those with serious mental illness suffer from significant negative emotions (Arksey, 2002, Arksey, 2003, Ashworth and Baker, 2000). They worry about the future (Rose, Mallinson, \& Gerson, 2006) and their relative's mental health (Hadrys, Adamowski, and Kiejna (2011) and they note feelings of tension and anxiety (Shankar \& Muthuswamy, 2007). They struggle with sadness and grief (Rose et al., 2006), and they have been reported to be at risk for major depressive symptoms (Wittmund, Wilms, Mory, \& Angermeyer, 2002).

For this study, emotional distress has been conceptualized as including anger, anxiety, and depression (Pilkonis et al., 2011). Studies of those negative emotions in family members of persons with mental illness have suggested that emotional experiences may vary depending on several factors, including their age, years of caregiving experience, relationship to the care recipient, and the stage of psychiatric illness of their relative (Karp and Tanarugsachock, 2000, Shankar and Muthuswamy, 2007). However, no studies have systematically examined the associations between women caregivers' anger, anxiety, and depression and the personal characteristics of the women, including age, race/ethnicity, and education; the characteristics of the person with the mental illness, including age, diagnosis, and time since first diagnosed; and features of the family situation, including the relationship between the caregiver and the person with mental illness, the residence of the mentally ill person (the same household or not), and receipt of direct, personal care by the family member or not.

The study reported here systematically investigated these associations using data from a larger study of women family members of adults with serious mental illness, whose results have been reported elsewhere (Zauszniewski et al., 2008, Zauszniewski et al., 2009a, Zauszniewski et al., 2009b). The larger study found that: (1) specific aspects of the woman caregiver, the person with mental illness, and the family situation were associated with perceived burden, resourcefulness, and quality of life (Zauszniewski et al., 2008); (2) perceived burden, resourcefulness, and quality of life were associated, but differed caregiver by race/ethnicity (Zauszniewski et al., 2009a); and (3) perceived burden and positive cognitions have direct effects on resilience indicators (Zauszniewski et al., 2009b). However, data on negative emotions collected in the larger parent study have not previously been examined. Analysis of such data is critical to providing a fuller picture of the emotional experience of women family caregivers.

This study therefore addressed the following research questions:

1. Is there an association between women caregivers' emotional distress (anger, anxiety, and depression) and the personal characteristics of those women (age, race, ethnicity, and education)?

2. Is there an association between woman caregivers' emotional distress (anger, anxiety, and depression) and the characteristics of the person with the mental illness (age, diagnosis, and time since first diagnosed)?

3. Is there an association between women caregivers' emotional distress (anger, anxiety, and depression) and the family situation (relationship between women family member and person with mental illness, whether the person with mental illness is living in the same household, and whether the person is receiving direct, personal care by the woman family member)? 


\section{Methods}

\section{Design}

Data for this exploratory, descriptive study were obtained in a larger cross-sectional study of female family members of adults with serious mental illness, which has been published elsewhere (Zauszniewski et al., 2008, Zauszniewski et al., 2009a, Zauszniewski et al., 2009b). The original study was approved by the University Institutional Review Board.

\section{Sample}

The sample was composed of 60 women family members of adults who had a serious mental illness, defined as schizophrenia, bipolar disorder, major depressive disorder, or an anxiety disorder (see Zauszniewski et al., 2008, Zauszniewski et al., 2009a, Zauszniewski et al., 2009b). To be included in the study, the women family members had to be between 18 and 65 years of age and able to read and understand English. They were recruited in northeast Ohio through advertisements posted in community mental health centers, local churches, and other venues, including grocery stores, department stores, restaurants, coffee houses, bookstores, libraries, and local support groups. The advertisement directed those who were interested in participating in the study to contact the researchers. The characteristics of the women family members, adults with mental illness, and family situation are summarized in Table 1.

Table 1. Characteristics of Women Family Members, Mentally III Adults, and Family Situation.

\begin{tabular}{|l|l|l|}
\hline Characteristics of women family members & & \\
\hline Age in years - mean (standard deviation) & & $46.28(11.71)$ \\
\hline Race/ethnicity - n (\%) & African American & $30(50 \%)$ \\
\hline & Caucasian & $30(50 \%)$ \\
\hline Education level - $\mathrm{n}(\%)$ & High school or less & $14(23 \%)$ \\
\hline & Some college/associate degree & $30(50 \%)$ \\
\hline Characteristics of person with mental illness & Bachelor's degree or higher & $16(27 \%)$ \\
\hline Age in years - mean (standard deviation) & & \\
\hline Years since first diagnosed - mean (standard deviation) $)$ & & $37.75(13.96)$ \\
\hline Diagnosis - $\mathrm{n}(\%)$ & Anxiety disorder (panic) & $11.21(9.65)$ \\
\hline & Bipolar disorder & $1(2 \%)$ \\
\hline & Depression & $27(45 \%)$ \\
\hline & Schizophrenia & $5(8 \%)$ \\
\hline Characteristics of family situation & & $27(45 \%)$ \\
\hline Relationship - $\mathrm{n}(\%)$ & Mother & \\
\hline & Sister & $24(40 \%)$ \\
\hline & Othera & $14(23 \%)$ \\
\hline Living arrangement - $\mathrm{n}(\%)$ & In same household & $22(37 \%)$ \\
\hline & In separate household & $24(40 \%)$ \\
\hline Assistance - $\mathrm{n}(\%)$ & Direct/personal care & $36(60 \%)$ \\
\hline & Indirect/support & $19(32 \%)$ \\
\hline
\end{tabular}

${ }^{a}$ other $=4$ aunts, 2 cousins, 7 daughters, 3 wives, 6 grandmothers.

The sample size for this secondary analysis was determined to be adequate based on a power analysis for examining descriptive trends reflecting substantial differences $(d=.80)$ by grouping (i.e. categorical) variables and correlations ( $r=.50$ ) between continuous variable, including emotional distress, at a significance level of $\alpha=.05$ and power of $B=.80$ (Cohen, 1992, Sapnas and Zeller, 2002). However, because the analysis required 
several statistical tests, which could result in detecting significant findings that occurred by chance, we considered an $\alpha$ of .01 as definitive and cautiously interpreted findings at .05 as suggestive of trends in the data (Cohen, 1992).

\section{Instruments}

The women family members who participated in the study completed a demographic questionnaire, which also asked for information about their relative with serious mental illness and their family situation, and a measure of emotional distress.

Emotional distress was measured by the Emotional Symptom Checklist (ESC) (Zauszniewski, Krafcik, et al., 2004, Zauszniewski, Morris, Preechawong and Chang, 2004). The 10 items comprising the ESC assess the presence of negative emotions within the past 2 weeks using a dichotomous (yes $=1 ;$ no $=0$ ) format. The 10 negative emotions listed include 3 reflecting anger (anger, restlessness, and irritability), 4 reflecting anxiety (anxiousness, nervousness, tension, and worry), and 3 reflecting depression (sadness, loneliness, and unhappiness). Total scores can range from 0 to 10, with ranges of 0 to 3 for anger, and 0 to 4 for anxiety, and 0 to 3 for depression; higher scores indicate greater emotional distress. Internal consistency estimates have ranged from .76 to .80 (Zauszniewski, Morris, Preechawong and Chang, 2004, Zauszniewski et al., 2006). Cronbach's $\alpha$ 's in this analysis were .76 (anger), .72 (anxiety), .71 (depression), and .73 (total scale). Factor analysis revealed the presence of three factors reflecting emotional distress (anger, anxiety, and depression) that explained $41 \%$ of the scale's variance (Zauszniewski et al., 2006). Evidence of construct validity included significant correlations in two studies between the ESC and the State Anxiety Inventory ( $r$ 's $=.51$ and .58 , respectively; $P<.001$ ) and the Center for Epidemiological Studies Depression Scale ( $r$ 's $=.53$ and .59 , respectively; $P<.001$ ) (Zauszniewski, Morris, Preechawong and Chang, 2004, Zauszniewski et al., 2006).

\section{Results}

We analyzed the components of emotional distress (anger, anxiety, and depression) by characteristics of the women family members, those of the relative with the serious mental illness, and those of the family situation. Depending on the level of measurement of the characteristic involved (i.e. categorical or continuous), the analyses performed included one way analysis of variance or correlations. The findings are reported in Table 2 and summarized briefly in the paragraphs below.

Table 2. Emotional Distress Symptoms Associated With the Characteristics of Women, Their Relative With Mental Illness, and Their Family Situation.

\begin{tabular}{|l|l|l|l|l|l|}
\hline Source & Characteristic & $\begin{array}{l}\text { Emotional } \\
\text { distress }\end{array}$ & Anger & Anxiety & Depression \\
\hline Women & Age (years) & $r=-.22 a$ & $r=-.23 a$ & $r=-.09$ & $r=-.17$ \\
\hline & Race/ethnicity & & & & \\
\hline & $\begin{array}{l}\text { African American } \\
(n=30)\end{array}$ & $\mathrm{M}=4.20$ & $\mathrm{M}=0.73$ & $\mathrm{M}=2.20$ & $\mathrm{M}=1.27$ \\
\hline & Caucasian $(\mathrm{n}=30)$ & $\mathrm{M}=3.67$ & $\mathrm{M}=1.06$ & $\mathrm{M}=1.40$ & $\mathrm{M}=1.20$ \\
\hline & $\mathrm{F}(1,59)$ & $\mathrm{F}=0.66$ & $\mathrm{~F}=1.35$ & $\mathrm{~F}=4.80 \mathrm{~b}$ & $\mathrm{~F}=0.05$ \\
\hline & Education & & & & \\
\hline & $\begin{array}{l}\text { High school or less } \\
(\mathrm{n}=14)\end{array}$ & $\mathrm{M}=3.68$ & $\mathrm{M}=1.00$ & $\mathrm{M}=1.43$ & $\mathrm{M}=1.43$ \\
\hline & Some college $(\mathrm{n}=30)$ & $\mathrm{M}=3.70$ & $\mathrm{M}=0.90$ & $\mathrm{M}=1.87$ & $\mathrm{M}=0.93$ \\
\hline & $\begin{array}{l}\text { Degree completed } \\
(\mathrm{n}=16)\end{array}$ & $\mathrm{M}=4.44$ & $\mathrm{M}=0.81$ & $\mathrm{M}=2.00$ & $\mathrm{M}=1.62$ \\
\hline & $\mathrm{F}(2,59)$ & $\mathrm{F}=0.44$ & $\mathrm{~F}=0.10$ & $\mathrm{~F}=0.63$ & $\mathrm{~F}=2.42 \mathrm{a}$ \\
\hline
\end{tabular}




\begin{tabular}{|l|l|l|l|l|l|}
\hline $\begin{array}{l}\text { Relative with mental } \\
\text { illness }\end{array}$ & Age (years) & $r=-.24 a$ & $r=-.08$ & $r=-.15$ & $r=-.28 b$ \\
\hline & Years since diagnosis & $r=-.38 b$ & $r=-.13$ & $r=-.44 * *$ & $r=-.14$ \\
\hline & Diagnosis & & & & \\
\hline & Bipolar disorder $(\mathrm{n}=27)$ & $\mathrm{M}=4.41$ & $\mathrm{M}=0.85$ & $\mathrm{M}=2.15$ & $\mathrm{M}=1.41$ \\
\hline & Schizophrenia $(\mathrm{n}=27)$ & $\mathrm{M}=3.18$ & $\mathrm{M}=0.82$ & $\mathrm{M}=1.26$ & $\mathrm{M}=1.11$ \\
\hline & $\mathrm{F}(1,53)$ & $\mathrm{F}=3.51 \mathrm{a}$ & $\mathrm{F}=0.02$ & $\mathrm{~F}=5.51 \mathrm{~b}$ & $\mathrm{~F}=0.94$ \\
\hline & Relationship & & & & \\
\hline & Mother $(\mathrm{n}=24)$ & $\mathrm{M}=4.54$ & $\mathrm{M}=1.00$ & $\mathrm{M}=2.04$ & $\mathrm{M}=1.50$ \\
\hline & Sister $(\mathrm{n}=14)$ & $\mathrm{M}=2.14$ & $\mathrm{M}=0.36$ & $\mathrm{M}=1.21$ & $\mathrm{M}=0.57$ \\
\hline & Other $(\mathrm{n}=22)$ & $\mathrm{M}=4.41$ & $\mathrm{M}=1.14$ & $\mathrm{M}=1.91$ & $\mathrm{M}=1.36$ \\
\hline & $\mathrm{F}(2,59)$ & $\mathrm{F}=5.22 *$ & $\mathrm{~F}=2.35 \mathrm{a}$ & $\mathrm{F}=1.55$ & $\mathrm{~F}=3.63 \mathrm{~b}$ \\
\hline & Living arrangements & & & & \\
\hline & Together $(\mathrm{n}=24)$ & $\mathrm{M}=4.38$ & $\mathrm{M}=0.83$ & $\mathrm{M}=2.00$ & $\mathrm{M}=1.54$ \\
\hline & Apart $(\mathrm{n}=36)$ & $\mathrm{M}=3.64$ & $\mathrm{M}=0,94$ & $\mathrm{M}=1.67$ & $\mathrm{M}=1.03$ \\
\hline & $\mathrm{F}(1,59)$ & $\mathrm{F}=1.22$ & $\mathrm{~F}=0.14$ & $\mathrm{~F}=0.75$ & $\mathrm{~F}=3.20 \mathrm{a}$ \\
\hline & Level of care & & & & \\
\hline & Direct $(\mathrm{n}=41)$ & $\mathrm{M}=4.32$ & $\mathrm{M}=0.47$ & $\mathrm{M}=1.74$ & $\mathrm{M}=0.89$ \\
\hline & Indirect $(\mathrm{n}=19)$ & $\mathrm{M}=3.10$ & $\mathrm{M}=1.10$ & $\mathrm{M}=1.83$ & $\mathrm{M}=1.39$ \\
\hline & $\mathrm{F}(1,59)$ & $\mathrm{F}=3.07 \mathrm{a}$ & $\mathrm{F}=4.29 \mathrm{~b}$ & $\mathrm{~F}=0.05$ & $\mathrm{~F}=2.66$ \\
\hline
\end{tabular}

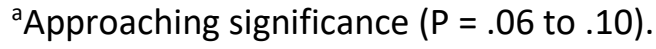

bSignificant at $\mathrm{P}<.05$.

$*$ Significant at $\mathrm{P}<.01$.

$* *$ Significant at $\mathrm{P}<.001$.

\section{Characteristics of Women Family Members}

The associations between emotional distress and the woman's age, race/ethnicity, or educational level were not significant. However, the correlation between the women's age and emotional distress approached significance $(r=-.22, P=.08)$, suggesting the possibility that younger women caregivers experience more emotional distress than older women. Interestingly, a similar finding emerged for anger symptoms $(r=-.23, P=.08)$, but not for anxiety or depressive symptoms. Although race/ethnicity and education were not associated with total emotional distress, Caucasian women reported more anxiety symptoms than African Americans $[F(1,59)=4.80$, $\mathrm{P}=.03$ ] and those who had attended college were somewhat less depressed than those who did had not attended college and those who completed a college degree.

\section{Characteristics of the Relative with Mental Illness}

Both the age of family members with mental illness and the number of years since they were first diagnosed (which were intercorrelated: $r=.44, \mathrm{P}<.001$ ), were associated with total emotional distress of the women caregivers ( $r$ 's $=-.24$ and $-.38, \mathrm{P}^{\prime} \mathrm{s}<.10$ and $<.01$, respectively). Younger age of the family member was correlated with depressive symptoms $(r=-28, P=.03)$ and the time since diagnosis was related to anxiety symptoms $(r=.44, \mathrm{P}<.001)$. In the analysis by diagnosis, we did not include data from women family members of persons diagnosed with depression or anxiety disorders because of the small numbers of persons in these categories. However, we found that having a relative with a diagnosis of bipolar disorder was more highly associated with women caregivers' emotional distress than having someone diagnosed with schizophrenia $[F(1,53)=3.51, P=.07]$. A similar, even stronger finding emerged in relation to anxiety symptoms $[F(1,53)=5.51, P=.02]$. 


\section{Characteristics of the Family Situation}

We examined associations between emotional distress and three aspects of the family situation: the relationship between the woman and the family member with mental illness, whether the two lived in the same household, and whether the care or assistance provided by the woman was direct (i.e., personal care) or indirect (i.e., psychological or instrumental support). We found that women who were siblings of the person with mental illness reported less emotional distress $[\mathrm{F}(2,59)=5.22, \mathrm{P}<.01]$, particularly in terms of depressive symptoms $[F(2,59)=3.63, P=.03]$ and anger symptoms $[F(2,59)=2.35, P=.10]$, than women who were mothers or others (aunts, cousins, daughters, and grandmothers). We also found that women living in the same household were more likely to report depressive symptoms $[F(1,59)=3.20, P=.08]$ than those living apart, although this was not significant. Providing direct care to a relative with mental illness was related to overall emotional distress $[F(1,59)=3.07, P=.08]$ but was more strongly associated with anger symptoms $[F(1,59)=4.29, P=.04]$.

\section{Discussion}

This study was the first to examine associations between emotional distress, specifically, anger, anxiety, and depressive symptoms, in women family members of relatives with serious mental illness and the women's personal characteristics (age, race, and education), the characteristics of adult relatives with SMI (age, diagnosis, and years since diagnosis), and their family situation (relationship, living arrangements, and care provided). We found that younger women family members experienced more anger and depressive symptoms than older women. These findings are similar to those of Magaña, Ramírez García, Hernández, and Cortez (2007), who found that among Mexican American caregivers, younger age was predictive of higher levels of depressive symptoms (Magaña et al., 2007).

We found that Caucasian women caregivers reported more anxiety symptoms than African Americans and this is consistent with previous research, which showed that Caucasian women family members reported greater perceived burden, greater strain, and greater family disruption than African-American women (Perlick et al., 2006, Zauszniewski et al., 2009a). In an earlier analysis, African-American women family members had higher scores than Caucasians on overall resourcefulness (Zauszniewski et al., 2009a), and that might explain the greater anxiety symptoms among Caucasians than among African Americans. In fact, other research has shown that greater resourcefulness is associated with more adaptive functioning, better perceived health, and greater quality of life (Huang et al., 2010, Lai et al., 2013, Zauszniewski et al., 2001, Zauszniewski et al., 2006).

We also found that those who had attended college expressed fewer depressive symptoms than those who did not attend college. Another study also found that lower levels of education were predictive of higher levels of caregivers' depressive symptoms, in Latino American caring for an adult with schizophrenia in Wisconsin, California, and Texas (Magaña et al., 2007).

In our study, number of years since diagnosis with mental illness was significantly correlated with caregivers' emotional distress. Furthermore, there was a strong positive correlation between time since diagnosis and anxiety symptoms. In a qualitative study by Shankar and Muthuswamy (2007), family caregivers whose mentally ill relative was in the early phase of illness expressed fear, loss of control, and helplessness, while those with a family member in the later phases expressed more despair, anger, anxiety and guilt. Karp and Tanarugsachock (2000) proposed that family members' emotions change over time in relation to their relative's course of mental illness. They suggest that once family caregivers are faced with having to accept the permanence of their family member's diagnosis and their inability to control the family member's behaviors, caregivers begin to experience negative feelings of anger, resentment, and even hate.

In our study, having a relative with a diagnosis of bipolar disorder was more highly associated with emotional distress in women caregivers than having someone diagnosed with schizophrenia. Further, a diagnosis of bipolar 
disorder in the relative was more highly associated with anxiety symptoms than a diagnosis of schizophrenia. These findings are in accordance with previous research, which showed that caregivers of persons with bipolar disorder experience high rates of both anxiety and depression (Perlick et al., 2005, Perlick et al., 2007).

We found that women who were siblings of the persons with mental illness reported less emotional distress, particularly in terms of anger and depressive symptoms, than women who were mothers or others (e.g., aunts, cousins, daughters, or grandmothers). Jiji (2007) has pointed out that siblings are likely to experience a range of emotional problems in response to the mental illness of a brother or sister. However, he noted that siblings may avoid intimate relationships to protect themselves from vulnerability and pain (Jiji, 2007) and this might explain our finding of less emotional distress among siblings than among mothers, who cannot avoid intimate relationships with their children.

Our findings also indicated that women caregivers living in the same household with the mentally ill family member were more likely to report depressive symptoms than those living apart. This is consistent with previous research on caregivers of persons with mental illness, which found that caregivers who were partners experienced greater distress and more burden than those who did not live with the person with mental illness (Goossens et al., 2008, Lam et al., 2005, Perlick et al., 2005).

The current study found that providing direct care to a relative with mental illness was somewhat related to emotional distress but more strongly associated with anger symptoms. Similarly, Jiji (2007) pointed out that providing personal care can interfere with socializing with friends and family and can result in a build- up of anger and resentment toward the person with mental illness (Jiji, 2007).

There were a number of limitations to this study. First, this was a secondary analysis of a cross-sectional study, which limited our ability to assess changes over time in study variables such us emotional distress. Second, the use of convenience sampling limits the generalizability of the findings. Third, the data were obtained through self-report-although it should be noted that the perspective of the respondent is important and this may justify the use of self-report. In addition, we also did not capture the emotional/behavioral state of the mentally ill family member at the time when the caregiver was interviewed, and thus may have had an impact on what caregivers reported in terms of emotional distress (Steele, Maruyama, \& Galynker, 2010). Finally, the sample size was modest.

Despite these limitations, the study findings provide direction for research and practice. Longitudinal research can explore changes in emotional distress over time especially since the course of illness differs for different mental illnesses. For example, the course with bipolar may have more fluctuations over time while the course of schizophrenia may be more chronic and stable. Future research might also use the PROMIS measure of emotional distress, which captures the same three dimensions, anger, anxiety, and depression, but also measures symptom severity. Future research should also include Hispanics/Latinos. Finally, future research needs to capture the emotional/behavioral state of the mentally ill family member when the caregiver is interviewed and assess its impact on how/what caregivers report in terms of emotional distress (Steele et al., 2010).

Implications for practice include the importance of identifying women caregivers who are at risk for emotional distress, namely those who are younger, who are Caucasian and who are less educated. The key challenge for professionals then is to minimize emotional distress and to maximize positive emotions through supportive and therapeutic interventions such as caregiver support groups, behavioral family therapy, stress management programs, psychoeducation, and respite care (Gray et al., 2009, Jardim and Pakenham, 2010, Macleod et al., 2011). Development and testing of tailored interventions for managing emotional distress are vital. In addition, there is a need to increase emphasis on a family systems approach to mental health care in nursing curricula at 
all levels. Nurses are in a strategic position to assess the emotional distress experienced by caregivers of persons with serious mental illness and provide tailored interventions to promote the optimal physical and mental health of caregivers, which can in turn influence the caregiving delivered to care recipients.

\section{Acknowledgment}

Funding for the study was provided by a Research Initiation Grant from the Frances Payne Bolton School of Nursing awarded to Dr. Jaclene A. Zauszniewski.

The authors acknowledge the editorial assistance of Elizabeth M. Tornquist of the University of North Carolina at Chapel Hill.

\section{References}

Angermeyer et al., 2006. M.C. Angermeyer, R. Kilian, H.U. Wilms, B. Wittmund. Quality of life of spouses of mentally ill people. International Journal of Social Psychiatry, 52 (3) (2006), pp. 278-285

Arksey, 2002. H. Arksey. Combining informal care and work: Supporting carers in the workplace. Health and Social Care in the Community, 10 (3) (2002), pp. 151-161

Arksey, 2003. H. Arksey. People into employment: Supporting people with disabilities and carers into work. Health and Social Care in the Community, 11 (3) (2003), pp. 283-292

Ashworth and Baker, 2000. M. Ashworth, A.H. Baker. 'Time and space': Carers' views about respite care. Health and Social Care in the Community, 8 (1) (2000), pp. 50-56

Burns et al., 2013. T. Burns, J. Catty, K. Harvey, S. White, I. Jones, S. McLaren, T. Wykes. Continuity of care for carers of people with severe mental illness: Results of a longitudinal study. The International Journal of Social Psychiatry, 59 (7) (2013), pp. 663-670, 10.1177/0020764012450996

Chan, 2011. S.W. Chan. Global perspective of burden of family caregivers for persons with schizophrenia. Archives of Psychiatric Nursing, 25 (5) (2011), pp. 339-349

Cohen, 1992. J. Cohen. A power primer. Psychological Bulletin, 112 (1992), pp. 155-159

Derogatis, 1993. L.R. Derogatis. Brief Symptoms Inventory (BSI): Administration, scoring and procedures manual. (3rd ed.), NCS Pearson, Inc., Minneapolis (1993)

Dixon et al., 2011. L. Dixon, A. Lucksted, D. Medoff, J. Burland, B. Stewart, A. Lehman, A. Murray-Swank. Outcomes of a randomized study of a peer-taught family-to-family education program for mental illness. Psychiatric Services, 62 (6) (2011), pp. 591-597, 10.1176/appi.ps.62.6.591

Dore and Romans, 2001. G. Dore, S.E. Romans. Impact of bipolar affective disorder on family and partners. Journal of Affective Disorders, 67 (2001), pp. 147-158

Fan and Chen, 2011. C.C. Fan, Y.Y. Chen. Factors associated with care burden and quality of life among caregivers of the mentally ill in Chinese society. International Journal of Social Psychiatry, 57 (2) (2011), pp. 195-206, 10.1177/0020764009348440

Goldberg, 1978. D.P. Goldberg. Manual of the general health questionnaire. Nfer (1978)

Goossens et al., 2008. P.J.J. Goossens, B.V. Wijngaarden, E.A.M. Knoppert-Van Der Klein, T.V. Achterberg. Family caregiving in bipolar disorder: Caregiver consequences, caregiver coping styles and caregiver distress. The International Journal of Social Psychiatry, 54 (2008), pp. 303-316

Gray et al., 2009. B. Gray, C.A. Robinson, D. Seddon, A. Roberts. An emotive subject: Insights from social, voluntary and healthcare professionals into the feelings of family carers for people with mental health problems. Health and Social Care in the Community, 17 (2) (2009), pp. 125-132

Hadrys et al., 2011. T. Hadrys, T. Adamowski, A. Kiejna. Mental disorder in Polish families: Is diagnosis a predictor of caregiver's burden? Social Psychiatry and Psychiatric Epidemiology, 46 (2011), pp. 363-372, 10.1007/s00127-010-0200-8

Huang et al., 2010. C.Y. Huang, S.E. Guo, C.M. Hung, S.L. Shih, L.C. Lee, G.C. Hung, S.M. Huang. Learned resourcefulness, quality of life, and depressive symptoms for patients with breast cancer. Oncology Nursing Forum, 37 (4) (2010), pp. 280-287, 10.1188/10.ONF.E280-E287 
Insel, 2008. T.R. Insel. Assessing the economic costs of serious mental illness. American Journal of Psychiatry, 165 (2008), pp. 663-665

Jardim and Pakenham, 2010. C. Jardim, K.I. Pakenham. Respite care for carers of adults with mental disorders: A qualitative investigation. Advances in Mental Health, 9 (2010), pp. 84-97

Jiji, 2007. T.S. Jiji. Family caregiving to psychiatric patients: Its impact on caregivers. Journal of Social Development, 3 (1) (2007), pp. 43-61

Jonas et al., 2012. D.E. Jonas, A.J. Mansfield, P. Curtis, J.H. Gilmore, L.C. Watson, S. Brode, B. Shetiman, et al. Identifying priorities for patient-centered outcomes research for serious mental illness. Psychiatric Services, 63 (2012), pp. 1125-1130, 10.1176/appi.ps.201100369

Karp and Tanarugsachock, 2000. D.A. Karp, V. Tanarugsachock. Mental illness, caregiving, and emotion management. Quality Health Research, 10 (1) (2000), pp. 6-25

Kim et al., 2003. H. Kim, J. Greenberg, M. Selzer, M. Krauss. The role of coping in maintaining the psychological well-being of mothers of adults with intellectual disability and mental illness. Journal of Disability Research, 47 (Parts 4/5) (2003), pp. 313-327

Lai et al., 2013. C.Y. Lai, J.A. Zauszniewski, T.C. Tang, S.Y. Hou, S.F. Su, P.Y. Lai. Personal beliefs, learned resourcefulness, and adaptive functioning in depressed adults. Journal of Psychiatric Mental Health Nursing (2013), 10.1111/jpm.12087 (in press)

Lam et al., 2005. D. Lam, C. Donaldson, Y. Brown, Y. Malliaris. Burden and marital and sexual satisfaction in the partners of bipolar patients. Bipolar Disorders, 7 (5) (2005), pp. 431-440

Lively et al., 2004. S. Lively, R.M. Friedrich, L. Rubenstein. The effect of disturbing illness behaviors on siblings of persons with schizophrenia. Journal of the American Psychiatric Nurses Association, 10 (2004), pp. 222232

Lucksted et al., 2013. A. Lucksted, D. Medoff, J. Burland, B. Stewart, L. Fang, C. Brown, L. Dixon. Sustained outcomes of a peer-taught family education program on mental illness. Acta Psychiatrica Scandinavica, 127 (4) (2013), pp. 279-286, 10.1111/j1600-0447.2012.01901.x

Macleod et al., 2011. S. Macleod, L. Elliott, R. Brown. What support can community mental health nurses deliver to carers of people diagnosed with schizophrenia? Findings from a review of the literature. International Journal of Nursing Studies, 48 (1) (2011), pp. 100-120, 10.1016/j.ijnurstu.2010.09.005

Magaña et al., 2007. S.M. Magaña, J.I. Ramírez García, M.G. Hernández, R. Cortez. Psychological distress among Latino family caregivers of adults with schizophrenia: The roles of burden and stigma. Psychiatric Services, 58 (3) (2007), pp. 378-384

Mak and Cheung, 2012. W. Mak, R. Cheung. Psychological distress and subjective burden of caregivers of people with mental illness: The role of affiliate stigma and face concern. Community Mental Health Journal, 48 (3) (2012), pp. 270-274

Manguno-Mire et al., 2007. G. Manguno-Mire, F. Sautter, J. Lyons, L. Myers, D. Perry, M. Sherman, G. Sullivan. Psychological distress and burden among female partners of combat veterans with PTSD. Journal of Nervous and Mental Disease, 195 (2) (2007), pp. 144-151

Møller et al., 2009. T. Møller, C.B. Gudde, G.E. Folden, O.M. Linaker. The experience of caring in relatives to patients with serious mental illness: Gender differences, health and functioning. Scandinavian Journal of Caring Sciences, 23 (1) (2009), pp. 153-160

Moller-Leimkuhlerm and Wiesheu, 2012. A. Moller-Leimkuhler, A. Wiesheu. Caregiver burden in chronic mental illness: The role of patient caregiver characteristics. European Archives of Psychiatry and Clinical Neuroscience, 262 (2) (2012), pp. 157-166, 10.1007/s00406-011-0215-5

Murray-Swank et al., 2007. A. Murray-Swank, S. Glynn, A. Cohen, M. Sherman, D. Medoff, L. Fang, L. Dixon. Family contact experience of family relationships, and views about family involvement in treatment among VA consumers with serious mental illness. Journal of Rehabilitation Research and Development, 44 (6) (2007), pp. 801-811

National Institute of Mental Health, 2008. National Institute of Mental Health. The numbers count: Mental disorders in America. Found online at http://www.nimh.nih.gov/health/publications/the-numberscount-mental-disorders-in-america/index.shtml\#Intro (2008) 
Perlick et al., 2005. D.A. Perlick, J.M. Hohenstein, J.F. Clarkin, R. Kaczynski, R.A. Rosenheck. Use of mental health and primary care services by caregivers of patients with bipolar disorder: A preliminary study. Bipolar Disorders, 7 (2005), pp. 126-135

Perlick et al., 2006. D.A. Perlick, R.A. Rosenheck, R. Kaczynski, M.S. Swartz, J.M. Cãnive, J.A. Lieberman. Components and correlates of family burden in schizophrenia. Psychiatric Services, 57 (8) (2006), pp. 1117-1125

Perlick et al., 2007. D.A. Perlick, R.A. Rosenheck, D.J. Miklowitz, C. Chessick, N. Wolff, R. Kaczynski, R. Desai. The STEP-BD Family Experience Collaborative Study Group: Prevalence and correlates of burden among caregivers of patients with bipolar disorder enrolled in the systematic treatment enhancement program for bipolar disorder. Bipolar Disorders, 9 (2007), pp. 262-273

Pernice-Duca, 2010. F. Pernice-Duca. Family network support and mental health recovery. Journal of Marital and Family Therapy, 36 (1) (2010), pp. 13-27

Pilkonis et al., 2011. P.A. Pilkonis, S.W. Choi, S.P. Reise, A.M. Stover, W.T. Riley, D. Cella. Items banks for measuring emotional distress from the Patient-Reported Outcomes Measurement Information System (PROMIS ${ }^{\circledR}$ ): Depression, anxiety, and anger. Assessment, 18 (3) (2011), pp. 263-283

Remko et al., 2013. M.M.R. Remko, S.E. Stutterheim, J.B. Pryor, G. Kok. Experiences of stigma by association among family members of people with mental illness. Rehabilitation Psychology, 58 (1) (2013), pp. $73-$ 80, $10.1037 / \mathrm{a} 0031752$

Rose et al., 2006. L.E. Rose, R.K. Mallinson, L.D. Gerson. Mastery, burden, and areas of concern among family caregivers of mentally ill persons. Archives of Psychiatric Nursing, 20 (1) (2006), pp. 41-51

Sapnas and Zeller, 2002. K.G. Sapnas, R.A. Zeller. Minimizing sample size when using exploratory factor analysis for measurement. Journal of Nursing Measurement, 10 (2002), pp. 135-154

Shamsaei et al., 2013. F. Shamsaei, S.M. Kermanshahi, Z. Vanaki, E. Hajizadeh, M.G. Holtforth, F. Cheragi. Health status assessment tool for the family member caregiver of patients with bipolar disorder: Development and psychometric testing. Asian Journal of Psychiatry, 6 (3) (2013), pp. 222-227, 10.1016/j.ajp

Shankar and Muthuswamy, 2007. J. Shankar, S.S. Muthuswamy. Support needs of family caregivers of people who experience mental illness and the role of mental health services. Families in Society: The Journal of Contemporary Social Services, 88 (2) (2007), pp. 302-310

Steele et al., 2010. A. Steele, N. Maruyama, I. Galynker. Psychiatric symptoms in caregivers of patients with bipolar disorder: A review. Journal of Affective Disorders, 121 (1-2) (2010), pp. 10-21

Taylor et al., 2008. J. Taylor, J. Greenberg, M. Selzer, F. Floyd. Siblings of adults and mild intellectual deficits or mental illness: Differential life course outcomes. Journal of Family Psychology, 22 (6) (2008), pp. 905-914

Tranvag and Kristofferson, 2008. O. Tranvag, K. Kristofferson. Experience of being the spouse/cohabitant of a person with bipolar affective disorder: A cumulative process over time. Scandinavian Journal of Caring Science, 22 (2008), pp. 5-18

Vaddadi et al., 2002. K. Vaddadi, C. Gilleard, H. Fryer. Abuse of carers by relatives with severe mental illness. International Journal of Social Psychiatry, 48 (2) (2002), pp. 149-155

Weimand et al., 2010. B.M. Weimand, B. Hedelin, C. Sallstrom, M.L. Hall-Lord. Burden and health in relatives of persons with severe mental illness: A Norwegian cross-sectional study. Issues in Mental Health Nursing, 31 (12) (2010), pp. 804-815

Wittmund et al., 2002. B. Wittmund, H.U. Wilms, C. Mory, M.C. Angermeyer. Depressive disorders in spouses of mentally ill patients. Social Psychiatry and Psychiatric Epidemiology, 37 (4) (2002), pp. 177-182

World Federation of Mental Health (WFMH), 2010. World Federation of Mental Health (WFMH)Caring for the caregiver: Why your mental health matters when you are caring for others. WFMH, Woodbridge VA (2010)

World Health Organization, 2013. World Health Organization. Schizophrenia. Retrieved on 13 July 2013. http://www.who.int/mental_health/management/schizophrenia/en/ (2013)

Zauszniewski et al., 2008. J.A. Zauszniewski, A.K. Bekhet, M.J. Suresky. Factors associated with perceived burden, resourcefulness, and quality of life in female family members of adults with serious mental illness. Journal of the American Psychiatric Nurses Association, 14 (2) (2008), pp. 125-135 
Zauszniewski et al., 2009a. J.A. Zauszniewski, A. Bekhet, M.J. Suresky. Relationships among perceived burden, depressive cognitions, resourcefulness, and quality of life in female relatives of seriously mentally ill adults. Issues in Mental Health Nursing, 30 (3) (2009), pp. 142-150

Zauszniewski et al., 2009b. J.A. Zauszniewski, A.K. Bekhet, M.J. Suresky. Effects on resilience qualities of women family caregivers of adults with mental illness: The role of positive cognitions. Archives of Psychiatric Nursing, 23 (6) (2009), pp. 412-422

Zauszniewski et al., 2001. J.A. Zauszniewski, C. Chung, K. Krafcik. Social cognitive factors predicting the health of elders. Western Journal of Nursing Research, 23 (5) (2001), pp. 490-503

Zauszniewski et al., 2006. J.A. Zauszniewski, K. Eggenschwiler, S. Preechawong, B.L. Roberts, D.L. Morris. Effects of teaching resourcefulness skills in elders. Aging and Mental Health, 10 (4) (2006), pp. 1-9

Zauszniewski, Krafcik, et al., 2004. J.A. Zauszniewski, K. Krafcik, S. Preechawong, C. Chung, T. Airey, P. Wilke, D.L. Morris, B.L. Roberts. Focused reflection: Reminiscence for elders using specific themes and visual images. Journal of the Applied Gerontology, 23 (4) (2004), pp. 429-442

Zauszniewski, Morris, Preechawong and Chang, 2004. J.A. Zauszniewski, D.L. Morris, S. Preechawong, H.J. Chang. Reports of depressive symptoms in elders with chronic conditions. Research and Theory for Nursing Practice: An International Journal, 18 (2/3) (2004), pp. 185-196

Zendjidjian et al., 2012. X. Zendjidjian, R. Richieri, M. Adida, S. Limousin, N. Gaubert, N. Parola, C. Lancon, L. Boyer. Quality of life among caregivers of individuals with affective disorders. Journal of Affective Disorders, 136 (3) (2012), pp. 660-665, 10.1016/j.jad.2011.10.011 